Andreász Kosztopulosz - Éva Kuruczleki (eds.) (2020): The Challenges of Analyzing Social and Economic Processes in the 21st Century. University of Szeged Faculty of Economics and Business Administration, Szeged, https://doi.org/10.14232/casep21c.6

\title{
The economy of Bulgarian Districts and its effect on environmental performance
}

\author{
Lyubomira Dimitrova
}

The aim of this study is to examine on the relationship between economic growth and environmental performance in the 28 Bulgarian districts for the period between 2010 and 2016. The results show that when in the cases where CO2 emissions are medium, the relationship with the economic growth is very weak. However, for those districts with higher $\mathrm{CO} 2$ emissions per capita there is a significant relation with the economic variables. This would mean that economic growth would have a strong effect on the air quality only after certain amount of $\mathrm{CO} 2$ emissions.

Keywords: environment, local economy, CO2 emissions, economic growth

\section{Introduction}

The relationship between economic growth and environmental conditions has been widely discussed in academic literature. Despite the common agreement that economic growth has an impact on the environment, there is still room for improvement in terms of finding the exact direction of the relationship and the main features that define it. So far, researchers have focused on the correlation between the two variables (Panayotou 2016, Suri-Chapman 1998), but the information on the exact relationship between the economy and the environment is scarce. The aim of this paper is to define those aspects of the local economy that have the strongest effect on the environmental performance using data for the 28 districts in Bulgaria between 2006 and 2017.

The paper begins with an overview of the literature, focusing on the economic growth in terms of its relations with the environmental quality and the way the relationship is described. The next step is to present the rationale behind the case selection, followed with a presentation of the dataset, containing all economic factors that may influence the environmental quality. Three regression models are build based on the $\mathrm{CO} 2$ emissions in the Bulgarian districts - the first uses districts with low $\mathrm{CO} 2$ emissions per capita, the second - with medium $\mathrm{CO} 2$ emissions and the third - with high $\mathrm{CO} 2$ emissions. Using stepwise regression I have selected only those economic variables that have the strongest effect on the environmental factors. The results show that there is a significant relationship between the $\mathrm{CO} 2$ emissions and the economic growth only in those cases where the emissions are the highest. 


\section{Economic growth and the environment}

When it comes to the effect of the economic performance on the environment, there are two competing schools of thought. The roots of this debate can be traced as back as the $19^{\text {th }}$ century when the boundaries, defining economic growth are set. As Romer (1994) suggests, the idea is that the economic growth describes a situation in which the economic input (resources plus labor) is always lower than the economic output. Since by definition resources are scarce, it seems likely that increases in economic input will lead to the exhaustion of all recourses. The negative externalities every human activity has on the environment also need to be taken into account (Stieglitz 1974).

The first side of the argument states that human action harms the environment, firstly due to the exploitation of natural resources, and secondly due to pollution that influences the climate (Beckerman 1992). The second one argues that the economic growth will have negative impact on the environment only until a certain point. After that, it will have a positive effect on the environment (Grossman-Krueger 1991). This relationship is known as the Environmental Kuznets Curve (EKC). Furthermore, as Julian Simon (1986) suggests, the price of all natural resources in the past decades shows no signs of their scarcity. And, as so far no know nonrenewable resource has disappeared completely, there is no reason to believe that human action could lead to such impact on the environment.

The claim of the first group of researchers is based on the understanding that the global economy and the goods produced are growing exponentially and that their relationship with environmental quality is strong, therefore at a certain point economic progress will lead to an environmental disaster. Meadows et al. (1972) predict that within six thousand years the economic and demographic development of the planet will reach their capacity, which will have fatal consequences. They point to the growing population, food production, consumption and use of inexhaustible resources as a potential cause. Accordingly, their solution is immediate intervention and policies that need to be implemented at the government level. Repeating their research in 1992, they came to the same conclusions, shortening the "disaster period" by a thousand years. Ehrlich and Holdren (1971) go even further, stating that each individual has a negative impact on the environment because of its own needs. The only way to protect the environment is to control the population and reduce technological progress. In his book "The stationary-state economy", Daly (1971) also argues that exploiting the planet's resources through overproduction and consumption will lead to a decline in wealth, despite rising incomes. The logical approach of the population in this context is to oppose any kind of economic activity, since any negative external impact will endanger their well-being.

The idea is that every human activity generates negative externalities for the environment, leading to its exhaustion. Stieglitz (1974) proposes a model of optimal consumption that will guarantee sustainable economic growth while protecting the environment from the depletion of natural resources. Others, such as Mishan and Mishan (1967), take an even more radical stance, challenging the need for economic growth. According to them, there is no link between personal well-being and rising consumption. 
Following this paradigm it is often assumed that investment in economic activities will also lead to negative consequences for the environment. Researchers such as Dasgupta and Heal (1979) propose investment control as a mechanism that would limit economic growth to "acceptable limits". Boons et al. (2009) add to this concept, focusing on direct private investment in developing countries. According to them, in the desire of their governments to attract the maximum amount of foreign capital, they neglect the possible negative impact on the environment. This, in turn, increases moral hazard, attracting companies that generally would not seek to maintain a clean nature.

In recent years, the focus of the discussion has shifted from limiting the human population and its access to commodities to finding alternative means of production. Sehrawat et al. (2015) claim the energy consumption and growth of household income as the main reasons behind the environmental degradation in India. In this case they operationalized the state of the environment solely through the $\mathrm{CO} 2$ emissions. Ladha et al. (2009) focus on the agricultural sector, arguing that conservation agriculture (farming system that promotes minimum soil disturbance) is the key factor for promoting limitation of the environmental footprint in South Asia.

The opposite position suggests that the relationship between environmental quality and economic growth is not exponential. Even though the two are related, the economic growth has a negative impact on the environmental quality only in the early stages of its development. Then after a certain point good economic performance actually leads to the improvement of the environment. This relationship is known in the literature as the Environmental Kuznets Curve (EKC) and was proposed for the first time by Grossman and Krueger in 1991, examining the effects NAFTA has on the environment in Mexico. Their results suggest that the trade relations between the USA and Mexico lead to a reduction of the pollution levels in Mexico City. The authors extend their study and in 1994 suggest that economic growth starts leading to less pollution around an income of 8000 USD per capita. Acaravci and Akalin (2015) came to a similar conclusion, claiming that the EKC can be observed only among developed countries opposed to developing ones.

Another argument in favor of the positive effect economic growth has on the environment is that wealthier societies are more likely to care more about problems such as biodiversity and pollution. Authors such as Beckerman (1992) argue that as personal income grows, so does the awareness regarding environmental conditions. Furthermore, access to clean water and sewerage systems should be considered more important than the discussion on limited natural resources. The change in the economic structure as the wealth increases is another factor, expected to have a positive effect on the environment (Jänicke-Binder-Mönch, 1997). On the other hand, the transition from agricultural to industrial economy is expecting to have more hazardous environmental effects (Van Alstine-Neumayer 2010). This shift in the attitudes towards environmental protection can therefore be seen as a positive externality of economic development.

The EKC has been an object of dispute ever since its introduction. By focusing on the relationship between economic growth and sulfur emissions, Perman and Stern (2003) show that when analyzing the long-term relationship between the 
two variables (for a period of 34 years) and using the appropriate statistical adjustments, the relationship described by the EKC is missing. Dasgupta et al. (2002) argue that the reason behind the environmental improvement following economic growth is not due to the relationship between the two variables, but rather the governance intervention and the promotion of more rigorous environmental regulations.

In the majority of cases comparison has been made either between large populations of different countries (Perman-Stern 2003, Arouri et al. 2012) or by observing a long period of time in the same country (Zhang-Cheng 2004, Stern 1993). However, Franzen, and Meyer (2009) have suggested that when studying the relationship between economic performance and environmental conditions it is better to use regional level data, as it is more precise and the comparison is more accurate. This could be difficult to implement, as the majority of environmental performance indicators are calculated on national level.

Following the discussion in the literature regarding the relationship between economic growth and environmental quality the following hypothesis is going to be tested:

\section{$\mathrm{H} 1$ : As economic growth increases the air quality will decrease.}

The hypothesis is built on the assumption of EKC and the work of scientists such as Beckerman (1992) and Alstine and Neumayer (2012). If the EKC holds this would mean that there is an optimal level of $\mathrm{CO} 2$ emissions and after it is reached the economic growth will improve the environmental quality.

The next sections of this paper are dedicated to the rationale behind the case selection, the operationalization of the variables, the scientific methods that are going to be used, data description, results and conclusions.

\section{Case selection}

In order to test the hypotheses of this research I will be using panel data from the 28 Bulgarian districts for the period 2010-2016. As Franzen and Meyer (2009) have suggested, when studying the relationship between economic performance and environment it is better to use regional level data, as it is more precise and the comparison is more accurate. The second reason is the economic diversity and inequality of Bulgarian districts. According to Ivanov (2018) the gap between the districts in terms of competitiveness has been increasing in recent years. Thus the dataset contains cases with both high and low levels of economic development. Third, the districts share the same regulatory framework thus omitting the effect different policy approaches can have on the economic-environment relations. 


\section{Operationalization}

The next step for hypothesis testing is to determine the indicators that are going to be used for the dependent and the independent variables of the models. As it was previously stated, usually when it comes to the operationalization of the environment, indicators such as $\mathrm{CO} 2$ emissions are used in the majority of cases. Unfortunately when the analysis is to be made on local level there is lack of indicators with which environmental quality could be measured. That is why $\mathrm{CO} 2$ emissions are going to represent the air quality of this study as well. However, as the variable is heteroscedastic the districts are going to be regrouped based on their $\mathrm{CO} 2$ emissions into three groups.

The level of economic growth has also been operationalized in various ways. In order to assure comprehensiveness I have included all the relevant economic indicators available in order to deduce them only to those that have the strongest impact on the economy or can explain to personal economic situation of the population. The initial number of independent economic variables are eleven: household access to the internet (percentage), number of enterprises (per 1000 inhabitants), tangible fixed assets investment (BGN per capita), foreign direct investment (FDI) (stock in BGN per capita), gross domestic product (GDP) (BGN per capita), mean wages (in BGN), average household income (in BGN), the share of the population living in material deprivation, the share of the population with tertiary education, unemployment rate and the share of people living below the poverty line. The data has been collected from the Bulgarian National Statistical Institute.

These indicators can be grouped in three categories based on their purpose. The first category is macroeconomic conditions (number of enterprises, tangible fixed assets investment, FDI, GDP and production value added). They have been used in the past to study the effect on the environment by scholars such as Low (2016), Asghari (2013) and Zhengge (2008). The second category is related to the economic situation on a household level (wages, income, access to the internet, material deprivation, unemployment and poverty rate). Such an approach has been used in the past in the empirical work of Fleury-Bahi et al. (2017), Gyourko et al. (1999) and Lipfert (2004). The last category contains those variables that are related to the education of the population (percentage of the population with higher education diploma). The relation between this indicator and the environmental quality has been studies by Sacks et al. (2010) and Farzin et al. (2006).

\section{Methods used}

The method that is going to be used is linear regression analysis. As there are three dependent variables describing the environmental performance, three regression models are going to be built.

As the initial number of independent variables is fourteen, the first thing to do is to find a way to reduce the dimensionality. To do so I will use a stepwise regression model for determination of the most significant variables in terms of their effect on the environment. The next step is using a simple OLS model following the formula: 


$$
y_{i}=\beta_{0}+\beta_{1} x_{1}+\beta_{2} x_{2}+\cdots \beta_{n} x_{n}+\varepsilon
$$

Where $y_{i}$ is the environmental variable and $x_{n}$ is the corresponding economic variable plus error.

The next step is to standardize both the dependent and independent variables in order to perform the stepwise regression which will select only the most relevant economic indicators. This is done through calculation of the standardized regression coefficients for each variable.

$$
b_{j s t d}=b_{j}\left(\frac{s_{x j}}{s_{y}}\right)
$$

Where $s_{y}$ and $s_{x j}$ are the standard deviations for the environmental factors and the corresponding $\mathrm{j}$ is the corresponding economic indicators. This standardization enables the comparison between the independent variables. Then the next step is to begin the model adding an additional variable every time until it reaches the point where any additional variable will not lead to an improvement of the model.

\section{Data description}

As it was previously stated the indicators used to represent the environmental quality in the Bulgarian districts are the emissions of $\mathrm{CO} 2$ per capita and Table 1 gives information on the variable's distribution.

Table 1 Characteristics of the environmental indicator

\begin{tabular}{ll}
\hline & CO2 emissions per capita \\
\hline Mean & 5.7 \\
Med. & 1.2 \\
Min & 0.1 \\
Max & 75.8 \\
St. Dev. & 12.9
\end{tabular}

Source: Regional profiles dataset, IME

The data in Table 1 illustrates the inequality between the Bulgarian districts in terms of environmental performance. As can be seen the $\mathrm{CO} 2$ emissions per capita may vary from 0.1 tons per capita (Sofia region 2010) to 75.8 tons per capita (Stara Zagora 2011). This goes to show that the distribution in this case is not normal. Following the assumptions following the EKC the cases are going to be divided into three groups by their $\mathrm{CO} 2$ emissions. To handle the not normal distribution, the variable is going to be log transformed. 
Table 2 Characteristics of the three groups of districts, based on their $\mathrm{CO} 2$ emissions

\begin{tabular}{llll}
\hline & $\begin{array}{l}\text { CO2 emissions } \\
\text { per capita }<1 \\
\text { tones }\end{array}$ & $\begin{array}{l}\text { CO2 emissions } \\
\text { per capita }>1 \\
\text { and <9 tones }\end{array}$ & $\begin{array}{l}\text { CO2 emissions } \\
\text { per capita }>9 \\
\text { tones }\end{array}$ \\
\hline Mean & 0.4 & 3.0 & 31.9 \\
Med. & 0.3 & 2.8 & 31.4 \\
Min & 0.1 & 1.0 & 10.4 \\
Max & 1.0 & 8.9 & 75.8 \\
St. Dev. & 0.3 & & 20.2 \\
N cases & 88 & 84 & 24 \\
\hline
\end{tabular}

Source: Regional profiles dataset, IME

The independent variables are presented in three groups, and Table 3 summarizes the data on the macroeconomic indicators.

Table 3 Macroeconomic indicators

\begin{tabular}{lllll}
\hline & $\begin{array}{l}\text { GDP per } \\
\text { capita }\end{array}$ & $\begin{array}{l}\text { FDI per } \\
\text { capita }\end{array}$ & $\begin{array}{l}\text { Tangible fixes } \\
\text { assets invested } \\
\text { per capita }\end{array}$ & $\begin{array}{l}\text { Number of } \\
\text { enterprises per } \\
1000 \\
\text { inhabitants }\end{array}$ \\
\hline Mean & 8501 & 1684.4 & 1789.7 & 43.96 \\
Med. & 7464 & 1046.4 & 1505.0 & 40.61 \\
Min & 4785 & 64.5 & 457.9 & 29.00 \\
Max & 28465 & 9936.7 & 7160.4 & 88.20 \\
\hline
\end{tabular}

Source: National Statistical Institute

The data again show large differences between the cases. The difference between the highest (Sofia capital 2016) and the lowest (Silistra 2010) GDP per capita is nearly $500 \%$. When it comes to the FDI the distribution across districts is even more visible, as this difference reaches $15305 \%$. The situation with the investment in tangible assets is similar, as in the case of Kardzhali in 2010 (457.9 BGN) they are $1463 \%$ less than in Sofia region in 2016 (2768 BGN). Based on this extreme values the distribution of enterprises between the districts is more homogeneous.

The state of inequality between districts becomes even more evident from the household data. Both income and wages vary significantly across cases, as the latter jumps from 5422 BGN minimum mean wage in Vidin in 2010 to 15658 BGN in Sofia (capital) in 2016. The lowest income for the period has been registered in Targovishte in 2010 (2354 BGN) and the highest - in Sofia (capital) in 2015 (7441 BGN). 
Table 4 Household economic characteristics

\begin{tabular}{lllllll}
\hline & Income & Wages & $\begin{array}{l}\text { People living } \\
\text { with material } \\
\text { deprivation } \\
(\%)\end{array}$ & $\begin{array}{l}\text { People } \\
\text { living } \\
\text { below the } \\
\text { poverty } \\
\text { line }(\%)\end{array}$ & $\begin{array}{l}\text { Access } \\
\text { to } \\
\text { internet } \\
(\%)\end{array}$ & $\begin{array}{l}\text { Unemploy } \\
\text { ment (\%) }\end{array}$ \\
\hline Mean & 4091 & 7720 & 41.69 & 25.62 & 46.98 & 12.41 \\
Med. & 4008 & 7420 & 40.95 & 24.26 & 47.95 & 12.00 \\
Min & 2354 & 5422 & 11.30 & 5.70 & 11.50 & 1.70 \\
Max & 7441 & 15658 & 76.30 & 60.13 & 75.30 & 28.80 \\
\hline
\end{tabular}

Source: National Statistical Institute

The variance in the share of the population living in material deprivation is quite similar as their share is only $11.30 \%$ in Yambol in 2015 and $76.3 \%$ in Veliko Tarnovo in 2011. The lowest share of people living below the poverty line is registered in Sofia (capital) in 2013 (5.7\%) and the highest - in Kardzhali in 2014 (60.13). Kardzhali is also the region with the lowest unemployment rate (in 2016) with $1.7 \%$ and the region with the smallest percent of the population having access to the internet in $2010-11.5 \%$.

Table 5 Education variable

\begin{tabular}{ll}
\hline & Higher education \\
\hline Mean & 20.74 \\
Med. & 19.30 \\
Min & 8.90 \\
Max & 51.40 \\
\hline
\end{tabular}

Source: National Statistical Institute

The education characteristics of the Bulgarian districts follows similar pattern - Kardzhali is the region with the lowest share of people with tertiary education in 2011.

\section{Results}

In order to test the relationship between environmental quality and the economy, three models are built, based on the $\mathrm{CO} 2$ emissions per capita of the districts. To do so I first build linear regression models containing all the variables and then select the most significant ones through stepwise regression. In order to ensure the validity of the results I check the initial diagnostics of the models. First, I use a Variance inflation factor test to check for multicollinearity (if the variable has a score higher than 5, than it has a strong effect on the collinearity of the regression model). (Breaux et al. 2019). 
As two of the independent variables had higher score than 5 (mean wages and GDP per capita), they were excluded from the models. The linearity, homoscedasticity and normality tests were made via the residual plot, the scale-location plot and the QQ plot. Due to the not normal distribution of the dependent variable, it is going to be log transformed.

Table 6 gives an overall information on the full model using cases with lower $\mathrm{CO} 2$ emissions generated as the dependent variable and the results from the optimal model selected with the "regsubsets" package in RStudio.

Table 6 Results from the regression analysis of the "Low" $\mathrm{CO} 2$ emissions per capita group

\section{Model 1}

Model 2

\begin{tabular}{|c|c|c|}
\hline Access to internet & \multicolumn{2}{|l|}{$0.00(0.00)$} \\
\hline Number of enterprises & \multicolumn{2}{|l|}{$0.00(0.00)$} \\
\hline Tangible fixes assets investment & \multicolumn{2}{|l|}{$0.00(0.00)$} \\
\hline Foreign Direct Investment & $-1.0(0.01)^{* * *}$ & $0.0(0.00)^{* *}$ \\
\hline Income & $0.00(0.00)$ & $0.0(0.00)$ \\
\hline $\begin{array}{l}\text { Share of the population living in } \\
\text { material deprivation }\end{array}$ & $2.0(0.00) * *$ & $2.0(0.0) * * *$ \\
\hline Higher education & $12.00(0.3) * * *$ & $12.0(0.3)^{* * *}$ \\
\hline Unemployment & \multicolumn{2}{|l|}{$0.00(0.00)$} \\
\hline $\begin{array}{l}\text { Share of the population living } \\
\text { below the poverty line }\end{array}$ & \multicolumn{2}{|l|}{$0.00(0.00)$} \\
\hline$R 2$ & 0.44 & 0.43 \\
\hline Number of cases & 88 & 196 \\
\hline \multicolumn{3}{|c|}{$\begin{array}{l}\text { Entries are regression coefficients with standard errors in parentheses. The } \\
\text { dependent variable is the logarithm of the } \mathrm{CO} 2 \text { emissions per square kilometer. The } \\
\text { coefficients have been multiplied by } 100 \text { in order to interpret them as percentages. } \\
\operatorname{Pr}(>|\mathrm{z}|) * * *<0.01 * *<0.05 *<0.1\end{array}$} \\
\hline
\end{tabular}

Source: Author's calculation 
What can be seen from the results of the first two models is that when it comes to districts with low $\mathrm{CO} 2$ emissions, the most significant economic variables are the share of population living in material deprivation (where one percent increase leads to an increase of $\mathrm{CO} 2$ emissions of $2.0 \%$ per capita) and the share of people with tertiary education (where one percent increase leads to an increase of $\mathrm{CO} 2$ emissions of $2.0 \%$ per capita). Even though the relationship with FDI is significant, its effect is negligible.

Table 7 Results from the regression analysis of the "Medium" $\mathrm{CO} 2$ emissions per capita group

\begin{tabular}{|c|c|c|}
\hline & Model 3 & Model 4 \\
\hline Access to internet & \multicolumn{2}{|l|}{$0.00(0.00)$} \\
\hline Number of enterprises & \multicolumn{2}{|l|}{$1.0(0.01)$} \\
\hline Tangible fixes assets investment & \multicolumn{2}{|l|}{$0.00(0.00)$} \\
\hline Foreign Direct Investment & $0.00(0.00)$ & $0.00(0.00)^{*}$ \\
\hline Income & $0.00(0.00)^{* * *}$ & $0.00(0.00)^{* *}$ \\
\hline $\begin{array}{l}\text { Share of the population living in } \\
\text { material deprivation }\end{array}$ & $0.00(0.00)$ & $1.0(0.05)^{* * *}$ \\
\hline Higher education & \multicolumn{2}{|l|}{$1.0(0.02)$} \\
\hline Unemployment & \multicolumn{2}{|l|}{$0.00(0.02)$} \\
\hline $\begin{array}{l}\text { Share of the population living } \\
\text { below the poverty line }\end{array}$ & $2.0(0.00)^{* *}$ & $1.0(0.06)^{* * *}$ \\
\hline$R 2$ & 0.27 & 0.23 \\
\hline Number of cases & 84 & 84 \\
\hline \multicolumn{3}{|c|}{$\begin{array}{l}\text { Entries are regression coefficients with standard errors in parentheses. The } \\
\text { dependent variable is the logarithm of the } \mathrm{CO} 2 \text { emissions per square kilometer. The } \\
\text { coefficients have been multiplied by } 100 \text { in order to interpret them as percentages. } \\
\operatorname{Pr}(>|\mathrm{z}|) * * *<0.01 * *<0.05 *<0.1\end{array}$} \\
\hline
\end{tabular}

Source: Author's calculation

What can be seen in Table 7 is that when districts with medium $\mathrm{CO} 2$ emissions per capita are used as cases, there are other independent variables with significant effect on them. In this case one percent increase in the population living in material deprivation leads to $1 \%$ increase in the $\mathrm{CO} 2$ emissions per capita. The same is valid for the share of people living below the poverty line. 
Table 8 Results from the regression analysis with $\mathrm{CO} 2$ emissions as dependent variable

\begin{tabular}{|c|c|c|}
\hline & Model 5 & Model 6 \\
\hline Access to internet & $0.00(0.01)$ & \\
\hline Number of enterprises & $-5.0(0.01)$ & $-5.0(0.01)^{* * *}$ \\
\hline Tangible fixes assets investment & $0.00(0.00)$ & \\
\hline Foreign Direct Investment & $0.00(0.00)^{*}$ & \\
\hline Income & $0.00(0.00)$ & \\
\hline $\begin{array}{l}\text { Share of the population living in } \\
\text { material deprivation }\end{array}$ & $0.00(0.0)$ & \\
\hline Higher education & $-3.0(0.02)$ & $-3.0(0.02)$ \\
\hline Unemployment & $-6.0(0.2) * * *$ & $-6.0(0.2) * * *$ \\
\hline $\begin{array}{l}\text { Share of the population living } \\
\text { below the poverty line }\end{array}$ & $0.02(0.01)$ & \\
\hline$R 2$ & 0.9 & 0.9 \\
\hline Number of cases & 24 & 24 \\
\hline \multicolumn{3}{|c|}{$\begin{array}{l}\text { Entries are regression coefficients with standard errors in parentheses. The } \\
\text { dependent variable is the logarithm of the } \mathrm{CO} 2 \text { emissions per square kilometer. The } \\
\text { coefficients have been multiplied by } 100 \text { in order to interpret them as percentages. } \\
\operatorname{Pr}(>|\mathrm{z}|) * * *<0.01 * *<0.05 *<0.1\end{array}$} \\
\hline
\end{tabular}

Source: Author's calculation

The models using the cases with the highest $\mathrm{CO} 2$ emissions per capita show the most significant results with $\mathrm{R} 2$ of 0.9 . The three variables that have the strongest effect on the dependent variable in that case are the number of enterprises, the share of people with tertiary education and the unemployment. Surprisingly enough, the results suggest that as the number of enterprises per capita increase by 1 this would lead to a decrease of the $\mathrm{CO} 2$ emissions per capita with $5.0 \%$. The reason for this results is that the most polluted Bulgarian district - Stara Zagora cannot be characterized with a wide number of enterprises. The other districts which are included in this category - Sofia (capital) and Varna have much more enterprises operating in their territory but the $\mathrm{CO} 2$ emissions are lower than in Stara Zagora. 
Following the same logic, there is negative relationship between unemployment and $\mathrm{CO} 2$ emissions - with one percent increase in the former the latter is expected to decrease by $6 \%$. This also follows to show that as the economic situation improves the $\mathrm{CO} 2$ emissions tend to decrease but only for those cases where the values are already high.

The results from the regression analysis suggest that the relationship between the economy and the environment is the most significant for those cases where the $\mathrm{CO} 2$ emissions are the highest. Following the conclusions from the last two models it is possible to conclude that as the economy grows the $\mathrm{CO} 2$ emissions will decrease only in those cases, where the emissions are already high. Following the R2 coefficients, it can be seen that the correlation between the variables is the strongest within districts with very low and very high $\mathrm{CO} 2$ emissions. In districts with low $\mathrm{CO} 2$ emissions, the share of people living in material deprivation and the share of people with tertiary education are the variables that have the strongest effect on the dependent variable.

\section{Conclusions and final remarks}

The aim of this study was to find those economic factors that have the strongest impact on the environment. The results from the regression analysis suggest that variables such as the share of the population with access to internet, the investment in tangible fixes assets and the household income do not have effect on the $\mathrm{CO} 2$ emissions despite the set of cases selected.

Despite the common assumption that economic activity has a negative influence on the environment, the results cannot support this claim for neither the districts grouped by $\mathrm{CO} 2$ emissions. Thus the hypothesis of this study cannot be supported for the low, medium and high $\mathrm{CO} 2$ emissions groups. On the other hand what can be seen is that the environment-economy relation does depend on the levels of air pollution - the economic conditions have positive effect on the environment for those cases where the $\mathrm{CO} 2$ emissions per capita is already high.

As it was mentioned earlier, the environmental - economic relation can be best observed on local level (Franzen-Meyer 2009). However, information on this level is extremely scarce, as usually composed indicators such as the Environmental Performance Index, developed by the Yale University are made only on country level and this is also the case for other environmental variables such as water and air quality plus deforestation. This raises the question about the necessity for the development of such indices on local level that could provide better measurement and thus would help us to present a better picture on the environmental-economic dynamics. Having said that, the data availability is a serious limitation for such researches. Additional information on the PM10 particles in the air, the biodiversity and pollution from other particles can give more comprehensive picture. Extending the time series that were included can also give further inside on the relation between economic and environmental performance. 


\section{References}

Acaravc1, A. - Erdogan, S. - Akalın, G. (2015): The electricity consumption, real income, trade openness and FDI: the empirical evidence from Turkey. International Journal of Energy Economics and Policy, 5, 4, 10501057.

Arouri, M. E. H. - Youssef, A. B. - M'henni, H. - Rault, C. (2012): Energy consumption, economic growth and $\mathrm{CO} 2$ emissions in Middle East and North African countries. Energy policy, 45, 342-349.

Asghari, M. (2013): Does FDI promote MENA region's environment quality? Pollution halo or pollution haven hypothesis. Int J Sci Res Environ Sci, 1, 6, 92-100.

Beckerman, W. (1992): Economic growth and the environment: Whose growth? Whose environment? World development, 20, 4, 481-496.

Boons, F. - Wagner, M. (2009): Assessing the relationship between economic and ecological performance: Distinguishing system levels and the role of innovation. Ecological Economics, 68, 7, 1908-1914.

Breaux, D. M. - Munyon, T. P. - Hochwarter, W. A. - Ferris, G. R. (2009): Politics as a moderator of the accountability-job satisfaction relationship: Evidence across three studies. Journal of Management, 35, 2, 307-326.

Daly, H. E. (1971): The stationary-state economy. Graduate School of Business, Department of Economics and Office for International Programs, University of Alabama.

Dasgupta, P. S. - Heal, G. M. (1979): Economic theory and exhaustible resources. Cambridge University Press.

Dasgupta, S. - Laplante, B. - Wang, H. - Wheeler, D. (2002): Confronting the environmental Kuznets curve. Journal of economic perspectives, 16, 1, 147168.

Ehrlich, P. R. - Holdren, J. P. (1971): Impact of population growth. Science, 171, 3977, 1212-1217.

Farzin, Y.H. - Bond, C. A. (2006): Democracy and environmental quality. Journal of Development Economics, 81, 1, 213-235.

Fleury-Bahi, G. - Pol, E. - Navarro, O. (eds.) (2017): Handbook of environmental psychology and quality of life research. Springer International Publishing.

Franzen, A. - Meyer, R. (2009): Environmental attitudes in cross-national perspective: A multilevel analysis of the ISSP 1993 and 2000. European sociological review, 26, 2, 219-234.

Grossman, G. M. - Krueger, A. B. (1991): Environmental impacts of a North American free trade agreement (No. w3914). National Bureau of Economic Research.

Gyourko, J. - Kahn, M. - Tracy, J. (1999): Quality of life and environmental comparisons. Handbook of regional and urban economics, 3, 1413-1454.

Ivanov, I. (2018): Study of regional inequalities: case of Bulgaria. Business, Management and Education, 16, 1, 27-39. 
Jänicke, M. - Binder, M. - Mönch, H. (1997): 'Dirty industries': Patterns of change in industrial countries. Environmental and resource economics, 9, 4, 467-491.

Ladha, J. K. - Kumar, V. - Alam, M. M. - Sharma, S. - Gathala, M. - Chandna, P. ... - Balasubramanian, V. (2009): Integrating crop and resource management technologies for enhanced productivity, profitability, and sustainability of the rice-wheat system in South Asia. Integrated crop and resource management in the rice-wheat system of South Asia, 69-108.

Lipfert, F. W. (2004): Air pollution and poverty: does the sword cut both ways? Journal of Epidemiology and Community Health.

Low, P. (2016): International trade and the environment. UNISIA, 30, 95-99.

Meadows, D. H. - Meadows, D. L. - Randers, J. - Behrens, W. W. (1972): The limits to growth. New York, 102, 27.

Mishan, E. J. - Mishan, E. J. (1967): The costs of economic growth (p. 112). Staples Press, London.

Panayotou, T. (2016): Economic growth and the environment. The environment in anthropology, 140-148.

Perman, R. - Stern, D. I. (2003): Evidence from panel unit root and cointegration tests that the environmental Kuznets curve does not exist. Australian Journal of Agricultural and Resource Economics, 47, 3, 325-347.

Romer, P. M. (1994): Economic growth and investment in children. Daedalus, 123, 4, 141-154.

Sacks, J. D. - Stanek, L.W. - Luben, T. J. - Johns, D.O. - Buckley, B.J. - Brown, J. S. - Ross, M. (2010): Particulate matter-induced health effects: Who is susceptible? Environmental health perspectives, 119, 4, 446-454.

Sehrawat, M. - Giri, A. K. - Mohapatra, G. (2015): The impact of financial development, economic growth and energy consumption on environmental degradation: Evidence from India. Management of Environmental Quality: An International Journal, 26, 5, 666-682.

Stern, D. I. (1993): Energy and economic growth in the USA: a multivariate approach. Energy economics, 15, 2, 137-150.

Stiglitz, J. (1974): Growth with exhaustible natural resources: efficient and optimal growth paths. The review of economic studies, 41, 123-137.

Suri, V. - Chapman, D. (1998): Economic growth, trade and energy: implications for the environmental Kuznets curve. Ecological economics, 25, 2, 195-208.

Van Alstine, J. - Neumayer, E. (2010): The environmental Kuznets curve. Handbook on Trade and the Environment, 2, 7, 49-59.

Zhang, X. P. - Cheng, X. M. (2009): Energy consumption, carbon emissions, and economic growth in China. Ecological Economics, 68, 10, 2706-2712.

Zhengge, T. (2008): The Coordination of Industrial Growth with Environment and Resource [J]. Economic Research Journal, 2, 3, 125-130.

Bulgarian National Statistical Institute (2019): https://www.nsi.bg/en/content/11223/statistical-data Accessed: 05.10.2019

Regional profiles (2019): https://www.regionalprofiles.bg/en/data/ Accessed: 05.10.2019 